\title{
Speciation of mercury in fly ashes by temperature programmed decomposition
}

M. Antonia Lopez-Anton ${ }^{a^{*}}$, Ron Perry ${ }^{a}$, Patricia Abad-Valle $^{b}$, Mercedes Díaz-Somoano $^{b}$, M. Rosa Martínez-Tarazona ${ }^{b}$ and M. Mercedes Maroto-Valer ${ }^{a}$ \footnotetext{
Spain

*Corresponding author (Present address)

Instituto Nacional del Carbón, C.S.I.C.

Francisco Pintado Fe, 26, 33011, Oviedo, Spain

Phone: +(34) 985119090

Fax: $\quad+(34) 985297662$

e-mail:marian@incar.csic.es
}

${ }^{a}$ Energy and Sustainability Research Division, Faculty of Engineering, University Park, University of Nottingham, Nottingham, NG7 2RD, United Kingdom

binstituto Nacional del Carbón, C.S.I.C. Francisco Pintado Fe, 26, 33011, Oviedo, 


\begin{abstract}
Mercury (Hg) is a toxic trace element which is emitted mostly in gas phase during coal combustion, although some Hg compounds may be retained in the fly ashes depending on the characteristics of the ashes and process conditions. To improve the retention of $\mathrm{Hg}$ in the fly ashes a good knowledge of the capture mechanism and $\mathrm{Hg}$ species present in the fly ashes is essential. The temperature programmed decomposition technique was chosen to identify the Hg species present in fly ashes obtained from two Pulverized Coal Combustion (PCC) plants and a Fluidized Bed Combustion (FBC) plant. The fly ashes were then used as $\mathrm{Hg}$ sorbents in a simulated flue gas of coal combustion and gasification. The Hg compounds found in the fly ash from the FBC plant after elemental mercury retention were mainly $\mathrm{HgCl}_{2}$ and $\mathrm{HgSO}_{4}$. The $\mathrm{Hg}$ species present in the two fly ashes from the two PCC plants were $\mathrm{HgCl}_{2}$ and $\mathrm{Hg}^{0}$. The $\mathrm{Hg}$ species formed in the coal gasification atmosphere was HgS for all three fly ashes. The only $\mathrm{Hg}$ compound identified in the fly ashes after the retention of mercury chloride was $\mathrm{HgCl}_{2}$.
\end{abstract}

Keywords: speciation, mercury, fly ashes 


\section{Introduction}

$\mathrm{Hg}$ is a persistent toxic pollutant that accumulates in the food chain [1]. Atmospheric $\mathrm{Hg}$ is a global problem with many natural and anthropogenic emission sources [2]. Coal-fired power plants are cited as one of the largest sources of $\mathrm{Hg}$ emissions to the environment [3]. As a consequence, legislative bodies in Europe and USA are considering reducing Hg emissions from coal-fired power plants [4-7]. A ruling to regulate $\mathrm{Hg}$ emissions from coal-fired power plants was announced in USA in line with the Clean Air Act of March 15, 2005 [7]. The USA regulatory structure for Hg emissions from coal-fired power plants is uncertain following the vacatur of EPA`s Clean Air Mercury Rule on February 8, 2008 [8], the U.S. Environmental Protection Agency (EPA), in collaboration with public and private research organizations, has fostered the development of a suite of $\mathrm{Hg}$ control technologies for coal-fired power plants [9].

Although various control technologies have been investigated, until now no costeffective or efficient control process has been developed for $\mathrm{Hg}$ removal in coal-fired power stations. Sorbents, such as activated carbons, are considered to be effective sorbents for Hg control in flue gases from coal combustion [10-13]. However, economic alternatives need to be developed. The growing interest in developing Hg capture systems has encouraged several research groups to determine the maximum level of retention that can be achieved by by-products from combustion plants. Recent research has shown that certain fly ash materials have an affinity for $\mathrm{Hg}$ and that a number of variables may influence Hg capture by fly ashes [14-21].

The speciation of $\mathrm{Hg}$ in fly ashes can provide valuable information for understanding the $\mathrm{Hg}$ retention mechanism in these by-products. One of the methods 
employed to speciate Hg in solid samples is thermally induced desorption. The thermal desorption method for $\mathrm{Hg}$ species takes advantage of the fact that the species can be arranged in increasing order (e.g. $\mathrm{HgCl}_{2}<\mathrm{HgS}<\mathrm{HgO}<\mathrm{HgSO}_{4}$ ) according to the temperature of desorption [22]. Thermal decomposition has been used to identify $\mathrm{Hg}$ compounds in soil contaminates, sediment samples, iron-based sorbents [23-25], and even in mercury lamp wastes [26]. However, there is a lack of a similar knowledge concerning the speciation of $\mathrm{Hg}$ in coal combustion products [27]. Milobowski et al. [28] conducted a study on samples obtained from wet flue gas desulfurization processes. The samples showed different thermal decomposition profiles. From the first profile, it was difficult to distinguish between $\mathrm{HgS}$ and $\mathrm{HgO}$, whereas the second curve corresponded well with $\mathrm{HgSO}_{4}$. When the thermal desorption method was employed by Rallo et al. [2930] to identify Hg species in gypsum from combustion and co-combustion plants several Hg species were identified. The most probable Hg species present in the gypsum samples were mercury sulphate and mercury halogenated compounds [29-30]. Feng et al. [31] showed that $\mathrm{Hg}^{0}, \mathrm{HgCl}_{2}, \mathrm{HgO}$, and $\mathrm{HgS}$ species exist in airborne particulate matter by means of thermal desorption. They also used the coal fly ash standard NIST 1633b to verify the quantitative analysis and suggested that the main $\mathrm{Hg}$ species in this standard was $\mathrm{HgCl}_{2}$ [31]. In their study on thermal Hg stability in fly ashes, Rubel et al. [32] found a good correlation between the mercury and sulphur contents, suggesting that the Hg may have been deposited on the ash as a sulphur compound. Similar results were found by Lopez-Anton et al. [33], indicating that mercury sulphur compounds were the most probable species present in two fly ashes from different power plants. 
In line with previous publications on temperature programmed decomposition [22, 29-30], the aim of the present work is to develop an experimental method for studying the thermally induced behaviour of the main Hg species in fly ashes. The fly ashes were used as Hg sorbents in different flue gas compositions.

\section{Experimental}

Three fly ash samples (CTA, CTSR, and CTP) were studied. CTA was obtained from a pulverized coal power plant (PCC) that uses a coal blend containing a high rank coal. CTSR was sampled from a PCC plant in which the coal blends contained bituminous coals. The third fly ash (CTP) was taken from a fluidised bed combustion plant (FBC) that burns coal mixtures and coal wastes with a high mineral matter content, and uses limestone in the bed. These fly ashes had been previously employed as sorbents of $\mathrm{Hg}^{0}(\mathrm{~g})$ and $\mathrm{HgCl}_{2}(\mathrm{~g})[19,34]$. The $\mathrm{Hg}$ species present in the gas atmosphere were obtained by evaporating $\mathrm{Hg}^{0}$ and $\mathrm{HgCl}_{2}$, respectively. Two synthetic gas mixtures, one with a gas composition containing species present in the coal gasification atmosphere (64\% $\mathrm{CO}, 3.7 \% \mathrm{CO}_{2}, 20.9 \% \mathrm{H}_{2}, 1.0 \mathrm{H}_{2} \mathrm{~S}, 4.0 \mathrm{H}_{2} \mathrm{O}$ ) and the other containing species present in the coal combustion atmosphere $\left(15 \% \mathrm{CO}_{2}, 9.2 \% \mathrm{O}_{2}, 0.2 \% \mathrm{SO}_{2}, 6.6 \% \mathrm{H}_{2} \mathrm{O}\right)$ were used in the retention experiments. A schematic diagram of the experimental device is shown in Figure 1. The results obtained in the two simulated flue gases were compared with those obtained in an inert atmosphere of $\mathrm{N}_{2}$.

To study the speciation of $\mathrm{Hg}$ in the fly ashes post-retention and in order to assign the Hg species to specific anions, a commercially available thermal dissociation module 
(PS Analytical Thermogram model 50.042) coupled to a mercury analyser (PS Analytical Sir Galahad Mercury Analyser model 10.525) was used. The Hg compounds present in the sample were carried through the oven tube in a stream of argon, at a flow rate of 250 $\mathrm{ml} \mathrm{min}{ }^{-1}$. The heating rate from room temperature to $650^{\circ} \mathrm{C}$ was nominally $10^{\circ} \mathrm{C} \min ^{-1}$ [22, 29-30]. A number of pure $\mathrm{Hg}$ compounds $\left(\mathrm{HgCl}_{2}, \mathrm{HgS}, \mathrm{HgSO}_{4}, \mathrm{HgO}\right)$ were first tested in order to determine their specific profiles so as to have a set of "fingerprints" which could serve as a standard of comparison for the profiles obtained from the fly ashes. The pure $\mathrm{Hg}$ compounds were diluted using a fly ash free of $\mathrm{Hg}$ to simulate the decomposition of Hg species in the fly ash samples.

The $\mathrm{Hg}$ content in the fly ashes was determined by means of an Automatic Mercury Analyser (AMA). The sulphur and chlorine contents were determined by an automatic analyser LECO SC-132 and ionic chromatography, respectively.

\section{Results and discussion}

\subsection{Thermal decomposition of mercury pure compounds in a matrix of fly ash}

As in previous studies carried out by Lopez-Anton et al. [22], a series of $\mathrm{Hg}$ standards was used to determine the specific thermograms of each species. In this study, in order to simulate the real behaviour of $\mathrm{Hg}$ in fly ashes, the pure $\mathrm{Hg}$ compounds were mixed in a matrix of mercury-free fly ash. Since certain constituents of the fly ash might affect the temperature of decomposition of the $\mathrm{Hg}$ species, the Hg standards were mixed with fly ash instead of with silica flour [22]. 
The compounds chosen were again those species which are most likely to form during coal combustion: $\mathrm{HgCl}_{2}, \mathrm{HgS}, \mathrm{HgO}$, and $\mathrm{HgSO}_{4}$ [28] (Figure 2). The sample blank-FA corresponds to the fly ash free of $\mathrm{Hg}$ and the thermogram obtained does not present any peak (Figure 2). The decomposition of $\mathrm{HgCl}_{2}$ occurs at temperatures ranging between 50 and $150^{\circ} \mathrm{C}$ with a maximum peak at approximately $85^{\circ} \mathrm{C}$. The next $\mathrm{Hg}$ compounds to decompose are the mercury sulphides between 170 and $330^{\circ} \mathrm{C}$. As noted by Lopez-Anton et al. [22], there are two different HgS crystalline structures: cubic black $\mathrm{HgS}$ or metacinnabar which decomposes at $265^{\circ} \mathrm{C}$ and trigonal red $\mathrm{HgS}$ or cinnabar which decomposes at $290^{\circ} \mathrm{C}[22,24]$. $\mathrm{HgO}$ and $\mathrm{HgSO}_{4}$ decompose at higher temperatures than mercury sulphides. $\mathrm{HgO}$ starts to decompose at approximately $200^{\circ} \mathrm{C}$, but presents a sharply defined peak at $430^{\circ} \mathrm{C}$. The thermal decomposition of $\mathrm{HgSO}_{4}$ is centered at $570^{\circ} \mathrm{C}$

The results obtained in the matrix of fly ash are summarized in Table 1 together with the results of a previous study for Hg pure compounds prepared in silica flour [22]. The temperatures of decomposition are similar, as are the temperature intervals. The thermal release of $\mathrm{HgCl}_{2}$ and red $\mathrm{HgS}$ in the fly ash matrix occurs at a slightly lower temperature than in the silica matrix, whereas that of $\mathrm{HgSO}_{4}$ occurs at a slightly higher temperature. Whereas metacinnabar (black HgS) presented two small peaks at 200 and $250^{\circ} \mathrm{C}$ in the silica matrix [22], in the fly ash matrix it exhibited only one peak with a small shoulder (Table 1, Figure 2). The behaviour of $\mathrm{HgO}$ in the fly ash matrix is especially noteworthy because its interval of decomposition is wider that of the $\mathrm{HgO}$ in silica with the maximum peak appearing at a lower temperature (Table 1). This suggests 
that the thermal release of $\mathrm{HgO}$ may have been influenced by a component or components of the fly ashes.

Although variations in Hg thermal desorption do occur, depending on heating rates and carrier gas flow rates employed, the results of this study confirm the previous findings by Lopez-Anton et al. [22] and Feng et al [31] for fly ashes where the order of Hg desorption temperatures is $\mathrm{HgCl}_{2}<\mathrm{HgS}<\mathrm{HgO}$.

\subsection{Analysis of mercury species in fly ashes post-retention}

In order to confirm the results of the previous studies carried out by Lopez-Anton et al. [19, 34] in which fly ashes were used as sorbents for Hg retention in combustion and gasification atmospheres, the temperature programmed decomposition method was employed to identify the $\mathrm{Hg}$ species formed in the different atmospheres. Figures 3-6 show the thermal decomposition profiles of the fly ashes obtained post-retention of $\mathrm{Hg}^{0}$ and $\mathrm{HgCl}_{2}$ in inert, combustion and gasification atmospheres. In previous experiments by Lopez-Anton et al. [19] the retention of Hg in fly ashes was greatly influenced by the gas composition. The amount of $\mathrm{Hg}^{0}$ captured in the gasification atmosphere and in $\mathrm{N}_{2}$ was similar, the highest capture being achieved in the combustion atmosphere [19]. However, when the source of mercury was $\mathrm{HgCl}_{2}$, the retention was similar in all three atmospheres [34].

The thermal decomposition of the Hg compounds in the three fly ash samples after $\mathrm{Hg}^{0}$ retention in the $\mathrm{N}_{2}$ atmosphere occurs at a low temperature ranging from approximately 50 to $150{ }^{\circ} \mathrm{C}$ (Figure 3). According to the decomposition temperatures for different $\mathrm{Hg}$ compounds (Table 1), $\mathrm{HgCl}_{2}$ should be the main $\mathrm{Hg}$ compound present in 
the three fly ashes under inert atmosphere. Some of the fly ash components may oxidize $\mathrm{Hg}^{0}$ to $\mathrm{Hg}(\mathrm{II})[17,19]$, favouring the reaction with the chloride. Table 2 shows the chlorine content together with the sulphur and mercury contents of the fly ashes. The CTP fly ash has a second peak at approximately $580^{\circ} \mathrm{C}$, suggesting that $\mathrm{HgSO}_{4}$ is also present in this fly ash (Figure 3, Table 2). However, the CTP sample was procured from a fluidized bed combustion plant (FBC) using limestone in the bed to retain $\mathrm{SO}_{2}$. Fly ash CTP can therefore be expected to show a higher sulphur content (Table 2), explaining why the $\mathrm{Hg}$ is present in the form of $\mathrm{HgSO}_{4}$ in this fly ash (Figure 3). The highest $\mathrm{Hg}$ signal corresponds to the CTSR fly ash from the power station that burns mainly bituminous coals and its high chloride content therefore would favour the formation of $\mathrm{HgCl}_{2}$ (Figure 3; Table 2). CTSR starts to decompose before $50^{\circ} \mathrm{C}$, at which point $\mathrm{Hg}^{0}$ may also be decomposing [31].

The Hg decomposition curve for CTP in the combustion atmosphere is similar to that obtained in the $\mathrm{N}_{2}$ atmosphere, suggesting that the same Hg species are present in both atmospheres (Figure 4, Table 1). The CTA and CTSR thermograms in the combustion atmosphere display broader and higher peaks than in the $\mathrm{N}_{2}$ atmosphere in accordance with the results for Hg retention [19]. Again the thermal decomposition of $\mathrm{Hg}$ starts before $50^{\circ} \mathrm{C}$ (Figure 4). Therefore, in addition to $\mathrm{HgCl}_{2}$, the presence of $\mathrm{Hg}^{0}$ cannot be ruled out.

Figure 5 shows the thermograms corresponding to the fly ashes after the retention of $\mathrm{Hg}^{0}$ in the gasification atmosphere. Desorption of the $\mathrm{Hg}$ compounds occurs at temperatures ranging from 150 to $350^{\circ} \mathrm{C}$. The temperatures corresponding to the decomposition of mercury sulphides (Table 1) are what one would expect in a 
gasification atmosphere containing $\mathrm{H}_{2} \mathrm{~S}$. In previous studies [19, 34], it was suggested that the $\mathrm{Hg}$ species formed in the $\mathrm{N}_{2}$ and gasification atmospheres were the same because the retention capacities in both atmospheres were similar. However, the results obtained from thermal desorption in this study show that, while $\mathrm{Hg}$ is present mainly as $\mathrm{HgCl}_{2}$ in the $\mathrm{N}_{2}$ atmosphere (Figure 3), in the gasification atmosphere it is in the form of $\mathrm{HgS}$ (Figure 5).

The retention of $\mathrm{Hg}$ by these three fly ashes using $\mathrm{HgCl}_{2}$ as the source of $\mathrm{Hg}$ under different atmospheres has also been studied by Lopez-Anton et al. [34]. Hg capture was found to be similar in most of the cases in all of the atmospheres studied. $\mathrm{HgCl}_{2}$ (g) might, therefore, be expected to be the species retained in the simulated combustion and gasification flue gas and in the inert atmosphere when $\mathrm{HgCl}_{2}$ is the source of $\mathrm{Hg}$ and indeed this was confirmed by thermal decomposition. As an example, Figure 6 illustrates the findings for fly ash CTA. As can be seen, the same Hg compound is present in the $\mathrm{N}_{2}$, combustion, and gasification atmospheres. The curves obtained from temperature programmed decomposition between $50-180^{\circ} \mathrm{C}$ suggest that $\mathrm{HgCl}_{2}$ is the only species present in the fly ashes studied (Table 1).

\section{Conclusions}

By employing a temperature programmed decomposition method, it was possible to identify the Hg species present in the different fly ashes studied. The Hg compounds present in the CTP fly ash from the FBC plant after the retention of elemental mercury in $\mathrm{N}_{2}$ and in a simulated flue gas from coal combustion were mainly $\mathrm{HgCl}_{2}$ and $\mathrm{HgSO}_{4}$. The Hg present in the CTA and CTSR fly ashes from the PCC plant could be $\mathrm{HgCl}_{2}$ but the 
presence of $\mathrm{Hg}^{0}$ cannot be ruled out. $\mathrm{HgS}$ was the $\mathrm{Hg}$ species formed in the coal gasification atmosphere in all three fly ashes. $\mathrm{HgCl}_{2}$ was the only $\mathrm{Hg}$ compound identified in the fly ashes after the retention of mercury chloride for all three atmospheres. Thus, in this study, thermal decomposition has proved to be a useful tool for helping to understand the mechanism of Hg retention in fly ashes.

\section{Acknowledgments}

The financial support for this work was provided by the projects CTM2004-04252.CO202/TECNO and MERG-CT-2004-516524 and Ministerio de Ciencia e Innovacion (programme of postdoctoral contracts abroad).

\section{References}

[1] J.H. Pavlish, Preface to the AQVI special issue of fuel processing technologies entitled: Air quality VI: Mercury, trace elements, SO3, particulate matter, and greenhouse gases. Fuel Process. Technol. 90 (2009) 1327-1332.

[2] R.K. Srivastava, N. Hutson, B. Martin, F. Princiotta, J. Staudt, Control of mercury emissions from coal-fired electric utility boilers, Environ. Sci. Technol. 1 (2006) 13851393.

[3] US EPA, United States Environmental Protection Agency, Clean Air interstate rule; 2005. Available from: http://www.epa.gov/interstateairquality/ 
[4] Commission of the European Communities. Commission staff working paper. Annex to the Communication from the Commission to the council and the European Parliament on Community Strategy Concerning Mercury Extended Impact Assessment $\operatorname{COM}(2005) 20$ final.

[5] US EPA. Mercury study report to congress. EPA-452/R-97-003, US EPA Office of Air Quality Planning and Standards. Washington DC: US Government Printing Office; December 1997.

[6] European Commission. Ambient air pollution by mercury Position paper; Office for official publications of the European Communities (KH-41-01-341-EN-N). ISBN 92894-2053-7, 2001.

[7] US EPA. United States Environmental Protection Agency, Clean Air mercury rule. March 15, 2005. Available from: http://www.epa.gov/mercuryrule.

[8] http://pacer.cadc.uscourts.gov/docs/common/opinions/200802/05-1097a.pdf.

[9] T.J. Feeley III, A.P. Jones, L.A. Brickett, B.A. O`Palko, C.E. Miller, J.T. Murphy, An update on DOE's Phase II and Phase III mercury control technology R\&D program, Fuel Process. Technol. 90(11) (2009) 1388-1391.

[10] K. Felsvang, R. Gleiser, G. Juip, K.K. Nielsen, Activated carbon injection in spray dryer/ESP/FF for mercury and toxics control, Fuel Process. Technol. 39 (1994) 417-430. [11] B. Ghorishi, B.K. Gullett, Sorption of mercury species by activated carbons and calcium-based sorbents: effect of temperature, mercury concentration and acid gases, Waste Manage. Res. 16 (1998) 582-593.

[12] S.J. Miller, G.E. Dunham, E.S. Olson, T.D. Brown, Flue gas effects on a carbonbased mercury sorbent, Fuel Process.Technol. 65-66 (2000) 343-363. 
[13] A.A. Presto, E.J. Granite, Impact of sulphur oxides on mercury capture by activated carbon, Environ. Sci. Technol. 41 (2007) 6579-6584.

[14] Z. Li, X. Luo, J.Y. Hwang, Unburned carbons from fly ash for mercury adsorption II: Adsorption Isotherms and Mechanisms, J. Min. Mat. Cgara Eng. 1 (2002) 79-96.

[15] F. Goodarzi, J.C. Hower, Classification of carbon in Canadian fly ashes and their implications in the capture of mercury, Fuel 87 (2008) 1949-1957.

[16] J.C. Hower, T. Sakulpitakphon, A.S. Trimble, G.A. Thomas, W.H. Schram, Major and minor element distribution in fly ash from a coal-fired utility boiler in Kentucky, Energy Sources Part A 28 (2006) 79-95.

[17] J.C. Hower, C.L. Senior, E.M. Suuberg, R.H. Hurt, J.L. Wilcox, E.S. Olson, Mercury capture by native fly ash carbons in coal-fired power plants, Prog. Energy Combust. Sci. 36 (2010) 510-529.

[18] M.A. Lopez-Anton, M. Diaz-Somoano, M.R. Martinez-Tarazona, Mercury retention by fly ashes from coal combustion: Influence of the unburned coal content, Ind. Eng. Chem. Res 46 (2007) 927-931.

[19] M.A. Lopez-Anton, M. Diaz-Somoano, M.R. Martinez-Tarazona, Retention of elemental mercury in fly ashes in different atmospheres, Energy Fuels 21 (2007) 99-103. [20] M.M. Maroto-Valer, D.N. Taulbee, J.C. Hower, Characterization of differing forms of unburned carbon present in fly ash separated by density gradient centrifugation, Fuel 80 (2001) 795-800.

[21] J.H. Pavlish, E.A. Sondreal, M.D. Mann, E.S. Olson, K.C. Galbreath, D.L. Laudal, S.A. Benson, Status review of mercury control options for coal-fired power plants, Fuel Process. Technol. 82 (2003) 89-165. 
[22] M.A. Lopez-Anton, Y. Yuan, R. Perry, M.M. Maroto-Valer, Analysis of mercury species present during coal combustion by thermal desorption, Fuel 89 (2010) 629-634. [23] C.C. Windmoller, R.D. Wilken, W.D.F. Jardim, Mercury speciation in contaminated soils by thermal release analysis, Water Air Soil Pollut. 89 (1996) 399-416.

[24] H. Biester, M. Gosar, S. Covelli, Mercury speciation in sediments affected by dumped mining residues in the drainage area of the Idrija Mercury Mine, Slovenia, Environ. Sci. Technol. 34 (2000) 3330-3336.

[25] M. Ozaki, M.dA. Uddin, E. Sasaoka, S. Wu, Temperature programmed decomposition desorption of the mercury species over spent iron-based sorbents for mercury removal from coal derived fuel gas, Fuel 87 (2008) 3610-3615.

[26] C. Raposo, C.C. Windmoller, W.A.D. Junior, Mercury speciation in fluorescent lamps by thermal release analysis, Waste Manage. 23 (2003) 879-886.

[27] J. Li, Y. Yuan, R. Perry, M.M. Maroto-Valer, Thermal desorption and speciation of mercury in fly ash, Prepr. Pap.-Am. Chem. Soc., Div. Fuel Chem. 52(2) (2007) 511-512. [28] M.G. Milobowski, G.T. Amrhein, G.A. Kudlac, D.M. Yurchison, Wet FGD Enhanced Mercury Control for Coal-fired Utility Boilers, The U.S. EPA/DOE/EPRI Combined Power Plant Air. Pollutant Control Symposium: "The Mega Symposium” Chicago, Illinois, USA, 2001.

[29] M. Rallo, M.A. Lopez-Anton, R. Meij, R. Perry, M.M. Maroto-Valer, Study of mercury in by-products from a Dutch co-combustion power station, J. Hazard. Mater. 174 (2010) 28-33. 
[30] M. Rallo, M.A. Lopez-Anton, R. Perry, M.M. Maroto-Valer, Mercury speciation in gypsums produced from flue gas desulfurization by temperature programmed decomposition, Fuel 89 (2010) 2157-2159.

[31] X. Feng, J.Y. Lu, D.C. Gregoire, Y. Hao, C.M. Banic, W.H. Schroeder, Analysis of inorganic mercury species associated with airborne particulate matter/aerosols: method development, Anal. Bioanal. Chem. 380 (2004) 683-689.

[32] A.M. Rubel, J.C. Hower, S.M. Mardon, M.J. Zimmerer, Thermal stability of mercury captured by ash, Fuel 85 (2006) 2509-2515.

[33] M.A. Lopez-Anton, P. Abad-Valle, M. Diaz-Somoano, M.R. Martinez-Tarazona, R. Perry, M.M. Maroto-Valer, Determination of mercury species in fly ashes by temperature programmed desorption, Proceedings of X Reunión del Grupo Español del carbón, ISBN 978-84-8458-308-0, (in Spanish), pag 195-196, Girona, Spain, 2010.

[34] M.A. Lopez-Anton, P. Abad-Valle, M. Diaz-Somoano, M.R. Martinez-Tarazona, Evaluation of the variables that influence mercury capture in solid sorbents, Coal Combustion and Gasification Products (doi: 10.4177/CCGP-D-09-00007.1) 1 (2009) 3237. 


\section{Captions of Figures}

Figure 1. Schematic diagram of the experimental device

Figure 2. Thermal decomposition profiles of model mercury compounds in a matrix of fly ash

Figure 3. Thermal decomposition profiles of fly ash samples in an inert atmosphere

Figure 4. Thermal decomposition profiles of fly ash samples in a coal combustion atmosphere

Figure 5. Thermal decomposition profiles of fly ash samples in a coal gasification atmosphere

Figure 6. Thermal decomposition profiles of CTA fly ash when $\mathrm{HgCl}_{2}$ is the source of mercury in an inert, combustion, and gasification atmosphere 